\title{
Microstructure characterization and thermal analysis of aluminum alloy B206 during solidification
}

\author{
N. Haghdadi ${ }^{1}$, A.B. Phillion ${ }^{1 *}$, D.M. Maijer ${ }^{2}$ \\ ${ }^{1}$ School of Engineering, The University of British Columbia, Kelowna, Canada \\ ${ }^{2}$ Department of Materials Engineering, The University of British Columbia, Vancouver, Canada
}

\begin{abstract}
The solidification kinetics of a high strength B206 aluminum casting alloy as a function of cooling rates between 1 and $15 \mathrm{~K} / \mathrm{min}$ has been characterized through a combination of differential scanning calorimetry (DSC), scanning electron microscopy (SEM), and optical microscopy. Three different peaks were detected in the DSC analysis, which corresponded to the nucleation of an $\alpha-\mathrm{Al}$ solid solution, an $\mathrm{Al}-\mathrm{Cu}-\mathrm{Fe}$ intermetallic and the eutectic phases. The presence of these phases was confirmed using a coupled scanning electron microscopy-energy dispersive spectroscopy (SEM-EDS) analysis. The $\alpha$-Al nucleation temperature was found to be independent of cooling rate while the eutectic and the intermetallic formation temperatures were depressed by up to $20 \mathrm{~K}$. The evolution of the fraction solid, particularly during the solidification of $\alpha$-Al was also affected by the cooling rate in such a way that slower cooling was accompanied by a higher fraction solid at a given temperature. Concurrently, microscopy was used in order to quantify the variation in secondary dendrite arm spacing (SDAS) with cooling rate for use in numerical simulations of casting processes.
\end{abstract}

Keywords: aluminum-copper alloys, differential scanning calorimetry, solidification kinetics, microstructure; fraction solid; secondary dendrite arm spacing

\section{Introduction}

In the interest of improving fuel efficiency and reducing emissions, it is imperative that aerospace and automotive industries reduce the weight of finished parts. In this regard, the substitution of aluminum alloys for ferrous components is viewed as a feasible means to realize weight saving, and has driven significant metallurgical research over the past few decades. A secondary advantage of this trend is improved passenger safety due to the higher energy absorbency of aluminum as compared to steel during vehicle collisions $[1,2]$. 
Although advanced wrought aluminum alloys can provide excellent combinations of properties, they are limited to relatively simple shapes. In order to make complex components, wrought alloys must be extensively machined and/or formed at significant expense. Alternatively, advanced aluminum casting alloys with improved mechanical properties can be formed into intricate parts through various shape casting processes. Aluminum casting alloys, based on the Al-Si binary alloy system such as A356 (Al-Si-Mg) and A319 (Al-Si-Cu), are commonly used in these applications due to their high fluidity and good castability [3]. But, as documented by Major and Sigworth [4], a recently-developed high-strength Al-Cu casting alloy, i.e. B206 ${ }^{1}$, offers significantly superior strength and toughness as compared to the conventional $\mathrm{Al}-\mathrm{Si}$ alloys while retaining good process yields.

In the AA 206 family of aluminum foundry alloys (i.e. 206, A206, and B206), the $\mathrm{Al}_{2} \mathrm{Cu}$ phase forms at temperatures close to the solidus [5], strongly limiting liquid metal flow during the late stages of solidification. Together with this alloy's long freezing range, the formation of $\mathrm{Al}_{2} \mathrm{Cu}$ results in a high susceptibility for hot tearing. After casting, 206-type alloys are typically heat treated in order to enhance properties. Unlike conventional Al-Si casting alloys, the optimal conditions for heat treating 206-type alloys are not yet well determined due to the need to control the combined effects of stress and corrosion acting on the $\mathrm{Cu}$-containing phases, in addition to achieving high strength. For example, Manivannan et al. [6] showed that in-service intergranular corrosion of B206 can be reduced by long artificial aging times at high temperatures (i.e. T7 temper designation), but this over-aged condition leads to a decrease in mechanical properties. Although the authors proposed a multi-stage heat treatment process to balance corrosion resistance and mechanical properties, significant cost savings could be achieved through better control over the solidification microstructure. Thus, in order to improve both casting yield and the heat treatment process, a detailed knowledge regarding the kinetics of solidification in B206 and the evolution of phase fractions is needed.

Many researchers have examined the effects of chemical composition on the solidification of Al-Cu foundry alloys. For instance, D'Elia et al. [7] added titanium-boron grain refiner to a B206 alloy, with the result being a significant decrease in grain size and a change from a dendritic to globular morphology. Kamali et al. [8] also found similar results for an Al-

\footnotetext{
${ }^{1}$ The B206 alloy has reduced levels $\mathrm{Ti}$ and Fe as compared to the traditional 206-type variant so that grain refinement via $\mathrm{TiB}_{2}$ will be effective.
} 
$4.5 \mathrm{Cu}-0.3 \mathrm{Mg}$ alloy, where the addition of $0.05 \mathrm{wt} \%$ Ti reduced the grain size and improved both hot tearing resistance and room temperature strength. In another study, Major and Sigworth [4] investigated the relationship between chemical composition, heat treatment and mechanical properties of various 206-type alloys. It was shown that traditional 206-type alloys have good ductility when heat treated to the T4 temper (solution treatment followed by water quenching and natural aging at room temperature for 7 days), whereas alloys with low levels of impurities like B206 require fast solidification rates and heat treatment to the T7 condition (solution treatment followed by water quenching and subsequent artificial aging at $200^{\circ} \mathrm{C}$ for 4 hours leading to an over-aged condition) in order to achieve comparable ductility. The formation of Fe-rich intermetallics is also important in 206-type alloys. Kamaga et al. [9] found that for B206, it is the $\mathrm{Si} / \mathrm{Fe}$ ratio and cooling rate which determine whether Fe-rich intermetallics are precipitated as $\beta(\mathrm{CuFe})$ or $\alpha(\mathrm{MnFe})$ phases. Liu et al. [10] showed that the addition of either Mn or Si in A206 helps to promote the formation of $\alpha$-Fe and hinders the precipitation of $\beta$-Fe. Elgallad et al. [11] also reported that the addition of $1.2 \% \mathrm{Si}$ can improve the hot tearing resistance of 206-type alloys, and leads to the precipitation of the $\mathrm{Al}_{15}(\mathrm{FeMnCu})_{3} \mathrm{Si}_{2}$ phase rather than the needle-like $\beta$ Fe phase.

Regarding the effect of cooling rate, Eskin et al. [12] established quantitative relationships between the average dendrite arm spacing, grain size and cooling rate for $\mathrm{Al}-\mathrm{Cu}$ alloys containing from 1 to $4 \% \mathrm{Cu}$, showing that dendrite arm spacing and grain size decreased with increasing cooling rate and copper concentration. Talamantes-Silva et al. [13] studied the microstructure variations in a 206-type alloy solidified under a thermal gradient, finding that the grain size and secondary dendrite arm spacing was decreased in regions that experienced higher cooling rates. Liu et al. [14] found that the volume fraction and solidification-start temperature increased for the $\alpha$-Fe precipitates with increasing cooling rate, but decreased for $\beta$-Fe.

Fraction solid evolution during solidification is another important factor during casting of aluminum alloys [15]. For shape casting, the evolution of the last ten percent of the solid, and the temperature range and fraction solid range over which the eutectic reaction takes place are of great importance due to their effect on casting quality and defects such as hot tearing and porosity [16]. The measurement of the kinetic effects related to the evolution in fraction solid at different cooling rates is difficult using conventional methods such as metallography but can be 
acquired in a straightforward manner through thermal analysis. In particular, differential scanning calorimetry (DSC) can be used to estimate the transformation temperatures in complex multicomponent systems. The challenges with the use of DSC in extracting these points have been previously studied in depth, especially in relation to determination of the solidus temperature [17-20].

As shown above, the literature contains a range of studies examining solidification microstructure in B206, and some preliminary work regarding solidification kinetics. However, there has not yet been a comprehensive study concerning the effects of cooling rate on this phase transformation. In particular, there is a lack of data linking the evolution of B206 fraction solid to cooling rate, and the critical temperatures for phase nucleation within the solidification sequence. In the current work, DSC is combined with microscopy in order to systematically study the solidification kinetics and microstructure of B206 aluminum casting alloys. The knowledge gained will be used to improve numerical models of B206 shape casting processes and ultimately improve the castability of this high-strength aluminum alloy.

\section{Experimental procedure}

The material used in these experiments was a cast B206 aluminum alloy provided by Natural Resources Canada - Canmet Materials Laboratory with a chemical composition of Al4.74Cu-0.25Mg-0.21Mn-0.05Si-0.06Fe-0.01Zn (wt\%). For the thermal analysis, a Netzsch STA 449 F3 heat flux thermo-gravimetric / differential scanning calorimeter (TG/DSC) instrument was employed. There are two crucibles inside a DSC furnace. One is for holding the sample and the other (empty) is used as a reference. The instrument functions by comparing the difference in voltage between two thermocouples (located under each crucible) during heating or cooling and then converting the signal to heat flow based on calibration using predetermined pure metal standards (In, Al, Ag, $\mathrm{Au}$ and $\mathrm{Ni}$ ) as reference materials.

Figure 1 depicts a typical curve obtained from a DSC instrument, showing the variation in heat flow between the sample and reference crucibles as a function of temperature. The methodology for measuring critical formation temperatures (i.e., the liquidus, pre-eutectic, and eutectic reactions), as well as the evolution in fraction solid with temperature is also illustrated. The critical temperatures are equal to the detectible deviations from the baseline in the DSC signal, while the evolution in fraction solid corresponds to the area under the characteristic 
peaks. According to [21], the onset temperature for a transformation can be taken from the DSC signal as the intersection of a linear fit to the downward sloping linear section of the transformation peak and a linear extrapolation of the baseline. In this case, as shown in Fig.1, the intersection of each pair of black lines corresponds to the critical formation temperatures. For calculating the evolution in fraction solid with temperature, the area under all three peaks is measured. Note that for solidification, the graph is read from right-to-left.

In order to characterize the solidification behaviour of B206, a series of thermal analyses were performed using the Netzsch DSC instrument. The process was to heat each sample to $50^{\circ} \mathrm{C}$ above the melting temperature and then to cool to room temperature at various cooling rates between 1 and $15 \mathrm{~K} / \mathrm{min}$. Alumina crucibles with lids were used for sample containers and highpurity $\mathrm{N}_{2}$ was used as a shielding gas. The measurements were then analyzed using the Netzsch Proteus (v6.0) software.

Additional preliminary tests were also conducted in order to determine the appropriate sample mass for experimentation. Figure 2 shows the results of these tests. By comparing the curve for the 10, 20 and $50 \mathrm{mg}$ specimens, it can be seen that sample mass strongly affect the results. If the sample is too large, there is a delay in the DSC measurement due to thermal mass, whereas if the sample is too small the critical temperatures and peak areas cannot be accurately estimated since the peaks are small in magnitude. For B206, it was found that samples of about $20 \mathrm{mg}$ provide the best compromise between the two extremes. Figure 2 also provides an indication of the reproducibility of the DSC cooling curves. By comparing the curves $5 \mathrm{~K} / \mathrm{min}$ and $5 \mathrm{~K} / \mathrm{min}$ (rear crucible), it can be seen that the results from the Netzsch DSC are reproducible since there is a mirror plane between the two curves. The difference in sign is due to the fact that the sample in the test $5 \mathrm{~K} / \mathrm{min}$ (rear crucible) was placed in the crucible normally used as the reference.

Finally, optical and scanning electron microscopy was performed on specimens following DSC analysis to examine the microstructures resulting from solidification under different cooling rates. Sample preparation involved mounting in cold cure resin, mechanical grinding to 1200 grit and polishing with $0.5 \mu \mathrm{m}$ alumina suspension, followed by etching using Keller's solution. A Tescan Mira3 XMU field emission scanning electron microscope (SEM) was used to investigate the microstructure of the examined material coupled with an Oxford AZtec X-Max energy 
dispersive spectroscope (EDS) system to identify the elements present in the different phase formed during solidification. The secondary dendrite arm spacing (SDAS) was measured through image analysis of optical micrographs.

\section{Results and discussion}

Solidification Sequence of B206

An overall assessment of the solidification sequence of metallic alloys can be performed using thermal analysis and metallography. Figure 3 shows a typical DSC trace depicting the heat flow during solidification of a B206 alloy cooled at a rate of $8 \mathrm{~K} / \mathrm{min}$. The first derivative of the heat flow curve with respect to temperature, dHeatFlow/dT, is also included. The phase transformations occurring during solidification were detected by means of the peaks observed in the heat flow curve. The onset of the transformations may be more accurately determined via the $\mathrm{dHeatFlow/dT}$ curve, which shows the deviations from a baseline heat extraction rate. Again, the intersection of linear fits of the transformation peak and the baseline signal is used to extract the transformation onset temperature. Three transformation onset temperatures can be identified in Figure 3 , at 643,557 and $530{ }^{\circ} \mathrm{C}$.

Based on Figure 3, along with a microstructural analysis presented in the next paragraph, it can be deduced that the solidification sequence of B206 occurs in three stages forming first primary aluminum dendrites, then the primary phase plus the pre-eutectic intermetallic, and finally the eutectic. At the first transformation onset temperature of $643{ }^{\circ} \mathrm{C}$, i.e. the liquidus temperature, the primary phase nucleates. Considering the chemical composition of the experimental alloy, this phase is the aluminum-rich $\alpha$ solid solution, which continues to solidify as the sample is further cooled. Upon reaching the second transformation onset temperature of $557{ }^{\circ} \mathrm{C}$, an Al-Cu-Fe intermetallic begins to form concurrently with the primary $\alpha$ phase. The formation of an iron-rich intermetallic is in line with the previous findings reported by Backerud [22] and Talamantes-Silva et al. [23], where the formation of iron-rich platelike $\mathrm{A} 17 \mathrm{Cu} 2 \mathrm{Fe} / \mathrm{A} 17 \mathrm{Cu} 2(\mathrm{FeMn})(\beta-\mathrm{Fe})$ intermetallics were reported during solidification of a 206-type aluminum alloy with low Fe content, in addition to the primary $\alpha$ phase and the eutectic. The quantitative results of the EDS analysis in the present study most-closely match the findings of Talamantes-Silva [23], and thus it can be hypothesized that the Fe-rich intermetallic formed during solidification of B206 is also Al7CuFe. However, as reported in [23], EDS results are 
only semi-quantitative and it is difficult to obtain a strong assessment of the stoichiometry of complex intermetallics such as $\mathrm{Al}-\mathrm{Cu}-\mathrm{Fe}$ due to the size of the particles, and the spatial resolution of the EDS technique. A detailed assessment of the effect of alloying elements and cooling rate on the formation of iron-rich intermetallics in 206-type alloys can be found in [24].

It is also noted that while the nucleation temperature for the $\beta$-Fe intermetallic has been reported to be $537^{\circ} \mathrm{C}$ in both [22] and [23], in this work it was found to be $\sim 557^{\circ} \mathrm{C}$. This difference in nucleation temperature may be attributed to the difference in cooling rate, as the cooling rates in both [22] and [23] are on the order of $60 \mathrm{~K} / \mathrm{min}$ while the onset temperatures identified in Figure 3 used a cooling rate of $8 \mathrm{~K} / \mathrm{min}$. As will be discussed in the next section, increasing the cooling rate depresses the nucleation temperature of the $\beta$-Fe intermetallic significantly. Backerud et al. [22] also found that the transformation temperature for this reaction was cooling-rate dependent, and determined that the transformation temperature for a similar alloy, A206, would vary between $537^{\circ} \mathrm{C}$ and $519^{\circ} \mathrm{C}$ as the cooling rate was increased from 18 $\mathrm{K} / \mathrm{min}$ to more than $200 \mathrm{~K} / \mathrm{min}$. At $8 \mathrm{~K} / \mathrm{min}$, it is thus expected for the transformation temperature to be higher than $537^{\circ} \mathrm{C}$, and $557^{\circ} \mathrm{C}$ is not unreasonable. A secondary factor affecting the $\beta$-Fe intermetallic nucleation temperature could be differences in alloy composition. Liu et al. [24] reported that the $\beta$-Fe intermetallic can precipitate over a range of temperatures between 590 and $530^{\circ} \mathrm{C}$ depending on the exact alloy composition.

In order to characterize the solidified microstructure of the specimens, scanning electron microscopy and EDS mapping was performed. Figure 4 shows the distribution of $\mathrm{Al}$ and $\mathrm{Cu}$ within the dendritic microstructure of B206. As can be seen, $\mathrm{Cu}$-rich eutectic forms during the late stages of solidification and thus ends up at the boundaries between grains. The small variation seen within the dendrite arms is due to micro-segregation, leading to a gradual increase in $\mathrm{Cu}$ content from the centreline of each dendrite to the periphery. In order to more accurately characterize the phases formed during solidification of the alloy, higher resolution SEM analysis coupled with EDS analysis was performed; the results are shown in Figure 5. As can be seen, the microstructure contains three main phases: the matrix $\alpha$-Al solid solution, a blocky eutectic copper-rich phase with the chemical composition of $\mathrm{Al}_{2} \mathrm{Cu}$ that is defined by the light grey colour (see Figure 5 (c)) and a Fe-containing intermetallic with a plate-like morphology (see 
Figure $5(\mathrm{~d})$ ). These findings are consistent with the results from the thermal analyses, which predicted the formation of the three distinct major phases.

The effect of cooling rate $(1,5$ and $15 \mathrm{~K} / \mathrm{min})$ on the DSC signals is presented in Figure 6. Upon initial examination, it is observed that the areas of the peaks are sensitive to the cooling rate with higher cooling rates resulting in larger peak areas. This phenomenon has been observed in previous studies as well. Wang and Davidson [25] attributed this to baseline curvature, while Larouche et al. [26] attributed the area of the peaks to the rate of heat flow in combination with the data acquisition rate of the DSC instrument. In Figure 6, the difference between the curves is significant and much larger than what one would expect due to variations in the baseline curvature. Thus, the explanation provided by Larouche would seem to be more appropriate.

Further analysis of the heat flow curves provides insight into the link between the transformation onset temperatures and cooling rates. Figure 7 shows a comparison between the different onset transformation temperatures as a function of cooling rate. As can be seen, the liquidus temperature $\left(\mathrm{T}_{1}\right)$ near $644^{\circ} \mathrm{C}$ is nearly independent of cooling rate. Both the pre-eutectic $\left(\mathrm{T}_{2}\right)$ and eutectic $\left(\mathrm{T}_{3}\right)$ temperatures, however, show a decreasing trend with increasing cooling rates. This is due to the diffusional nature of these transformations. The decrease in $T_{2}$ and $T_{3}$ without significant changes to the liquidus temperature results in an increase in the freezing range of the primary phase with increasing cooling rate. This also results in widening of the overall solidification range of the material. It is interesting to note that for AA5182 alloy, Thompson et al. [27] also reported that the primary phase formation temperature is independent of cooling rate while the eutectic and $\mathrm{Mg}_{2} \mathrm{Si}$ formation temperatures show a decreasing trend with increasing cooling rate.

\section{Evolution in Fraction Solid}

The evolution of fraction solid with temperature is shown in Figure 8 along with the first derivative $(\mathrm{d} f s / \mathrm{dT})$ curve for B206 solidifying at $8 \mathrm{~K} / \mathrm{min}$ (Figure 3$)$. The $(\mathrm{d} f s / \mathrm{dT}$ ) curve is negative since fraction solid evolves on cooling. As can be seen, there is a large increase in the rate of fraction solid evolution at each onset temperature, corresponding to the rapid growth of each phase that occurs after non-equilibrium nucleation. As discussed in [28], the range over which the eutectic transformation takes place is a critical factor in determining hot tearing 
susceptibility for B206 since larger ranges require larger amounts of irreversible strain to accommodate solidification shrinkage. For the conditions given in Figure 3, the eutectic fraction of B206 is about $4-5 \%$, and occurs over a temperature range of about $25{ }^{\circ} \mathrm{C}$.

As expected, the evolution of the fraction solid is also affected by the cooling rate. Figure 9 provides the change in fraction solid with temperature for five samples solidified under cooling rates between 1 and $15 \mathrm{~K} / \mathrm{min}$. As can be seen, the curves shift towards the left with increased cooling rate, i.e. towards lower temperatures. However, at temperatures below $\sim 540{ }^{\circ} \mathrm{C}$ and especially close to the eutectic reaction, one cannot see much difference between the fraction solids with different cooling rates. Figure 9 also indicates that higher cooling rates decrease the range of temperature over which the last $10 \%$ of the material solidifies. The variation in the eutectic fraction as a function of cooling rate is also an important parameter, which for aluminum alloys has been debated within the literature. Sarreal and Abbaschian [29] reported that the eutectic fraction increases with increasing cooling rate while Nafisi et al. [30] reported the reverse. The current data, however, shows that for cooling rates from 5 to $15 \mathrm{~K} / \mathrm{min}$ the fraction eutectic for the B206 alloy ranges between 4-5\% irrespective of the applied cooling rate. The experiment at a cooling rate of $1 \mathrm{~K} / \mathrm{min}$ showed a smaller value of fraction eutectic, approximately $3 \%$.

The limited or missing dependency on cooling rate for the fraction of eutectic may be due to the interplay between microstructural length-scale, microsegregation, and diffusion time. Flemings [31] noted that the cooling rate during solidification has little effect on the degree of microsegregation and hence on the amount of non-equilibrium eutectics. On the one hand, the characteristic length-scale of the microstructure obtained during fast cooling is quite small and the corresponding solute gradients are high. Hence the solid-state (back) diffusion is quite efficient, which decreases the degree of microsegregation [12]. On the other hand, upon slow cooling, the degree of microsegregation is also low because of a longer solidification time and correspondingly longer time available for diffusion [12]. Thus, whether slow or fast cooling is applied, similar amounts of eutectic will form. According to Eskin et al. [12], the most accepted rationale on this issue is as follows: under low cooling rates, the amount of non-equilibrium eutectic shows an increasing trend with increasing cooling rate due to limited diffusion in the solid, reaching a plateau for conditions close to the Scheil assumptions, and then again 
decreasing at very fast cooling rates around $102 \mathrm{~K} / \mathrm{s}$ and higher where there is hindered diffusion in the liquid phase and correspondingly solute trapping.

To gain more insight into the solidification kinetics of B206, solidification curves were generated using ThermoCalc assuming the limits of Lever (complete mixing in solid and liquid) and Scheil (no diffusion in the solid) conditions. As expected, the evolution in fraction solid with temperature for Scheil behaviour occurs at lower temperatures as compared to the equilibrium Lever rule. There is also an absence of eutectic formation in the equilibrium curve, although it does appear in the Scheil curve. Figure 10 additionally shows the experimentally-measured values at cooling rates of $1 \mathrm{~K} / \mathrm{min}$ and $15 \mathrm{~K} / \mathrm{min}$ for comparison purposes. In the case of the Lever rule predictions, the best-fit experimental data is from the measurement with a cooling rate of $1 \mathrm{~K} / \mathrm{min}$, while in the case of the Scheil predictions, the best-fit experimental data is from the measurement with a cooling rate of $15 \mathrm{~K} / \mathrm{min}$.

The good match between the experimental data at low cooling rates with the Lever rule predictions and the experimental data at high cooling rates with the Scheil predictions, in combination with the minimal variation in eutectic fraction seen experimentally provides additional strength to Eskin's argument [12] of a plateau in non-equilibrium eutectic fraction as long as the condition of infinite diffusion (or complete mixing) in the liquid is satisfied. Even at a cooling rate of $15 \mathrm{~K} / \mathrm{min}$, diffusion in the liquid is so fast that this condition is met. Nonetheless, there are still considerable deviations between the fraction solid predictions and experimental data. For the slow cooling rate, the small observed deviation is attributed to a combination of the undercooling required for nucleation and back diffusion in the solid. For the fast cooling rate, the large deviation at low fraction solid can be attributed to both to nucleation undercooling, and limitations in the apparatus since there is a thermal lag between the temperature of the DSC furnace and the sample. At $15 \mathrm{~K} / \mathrm{min}$, this thermal lag is noticeable when solidification begins due to the sudden release of latent heat.

\section{Cooling Rate - Secondary Dendrite Arm Spacing Relationship}

The microstructures obtained through the solidification of the experimental alloy under different cooling rates of 1, 5, 8 and $15 \mathrm{~K} / \mathrm{min}$ are depicted in Figure 11. The microstructures all exhibit features typical of dendritic solidification. The grey/white regions represent the primary 
dendrites while the black regions represent the eutectic and intermetallic phases. As can be seen, higher cooling rates result in a refined microstructure, specifically both the dendrite cell size and the secondary dendrite arm spacing (SDAS) decrease. The corresponding variation in SDAS with cooling rate is provided in Figure 12, along with prior results [32,33] for other $\mathrm{Al}-\mathrm{Cu}$ casting alloys. The observed decrease in the SDAS with cooling rate is in line with the previous studies, although the exact values are different.

Equations linking SDAS with cooling rate often take the form of SDAS $=C(C R)^{-n}$, where $C R$ is the cooling rate in $\mathrm{K} / \mathrm{s}$, and $C$ and $n$ are constants. Based on the curves shown in Figure 12, $C$ and $n$ for the B206 alloy were calculated to be $37 \mu \mathrm{m}$ and 0.325 , respectively. The $\mathrm{n}$ value is in good agreement with previous studies that report $n$ in the range of $0.29-0.39$ for binary Al-Cu alloys [34,35].

The observed decrease in the SDAS with cooling rate can be reasoned considering a number of factors. One is that the solid/liquid interface velocity increases with an increase in cooling rate [36], thus releasing more latent heat per unit time. The response of the system to the high cooling rate is to reduce dendrite arm spacing in order to increase the overall dendrite-arm surface area available for heat transport. Another is that the rate of cooling affects the spacing by controlling the time for diffusion and therefore the distance at which the solute diffuses around a growing dendrite-arm. In fast cooling, little time is available, the composition gradient is steep, and the average alloy composition is close to the composition of the growing arm. The result is smaller arm spacing [32]. For slower cooling rates or longer solidification times, coarsening will occur, removing small arms and growing larger arms with the result being larger dendrite arm spacing. Regardless of the mechanism, the fine dendrite arm spacing at faster cooling rates provides increased yield strength and improved fatigue resistance.

Finally, it is worth noting that when dealing with the issue of hot tearing in B206, the effect of cooling rate appears to be complex and requires further study. On one hand, a high solidification rate is accompanied by an increase in the temperature interval for solidification, does not provide enough time for liquid metal to alleviate casting strain [5], and thus increases hot tearing susceptibility. On the other hand, a high cooling rate induces microstructural refinement, which has been reported to decrease hot tearing [37]. Thus, it is likely that successful 
castings of B206 will be obtained when the process is designed such that solidification occurs quickly to reduce grain size but not so fast that the solidus becomes significantly depressed.

\section{Summary and Conclusions}

The solidification kinetics of the aluminum alloy B206 have been studied as a function of cooling rate from 1 to $15 \mathrm{~K} / \mathrm{min}$ using a combination of thermal analysis and microscopy. The solidification sequence of this alloy consists of three major transformations, which are related to the formation of primary aluminum, a pre-eutectic intermetallic, and the eutectic. The nucleation temperatures of the different phases showed different trends with variation in cooling rate. Although the liquidus temperature remains constant, the formation temperatures of the preeutectic and eutectic phases are coupled to the rate of heat extraction. A decrease in the latter temperatures was observed when the rate of solidification was increased, resulting in lengthening of the freezing range of the primary phase. The evolution of the fraction solid was also affected by the cooling rate, where increasing the cooling rate shifted the curves towards the left, i.e. towards lower temperatures. It was also found that high cooling rates during the solidification of the B206 alloy lead to significant microstructure refinement in terms of SDAS, and an equation linking the SDAS to cooling rate has been fit to the data.

\section{Acknowledgements}

The authors would like to thank the Natural Sciences and Engineering Research Council of Canada (NSERC) and partner companies within the Strategic Project "Through-Process Modelling: Castings for Marine Energy Systems" for funding this research. 


\section{Figures}

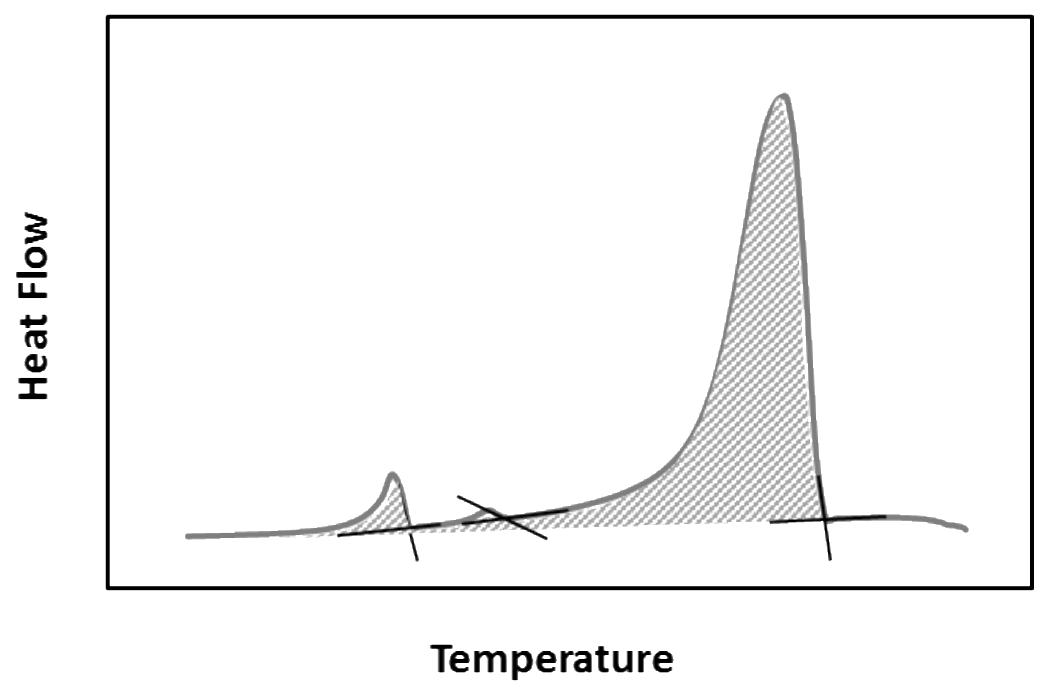

Figure 1 - Schematic illustration showing the methodology for deriving critical temperatures (i.e. the intersection of a linear fit to the downward sloping linear section of the transformation peak and a linear extrapolation of the baseline) and the evolution in solid fraction with temperature (i.e. area under the curve) during solidification.

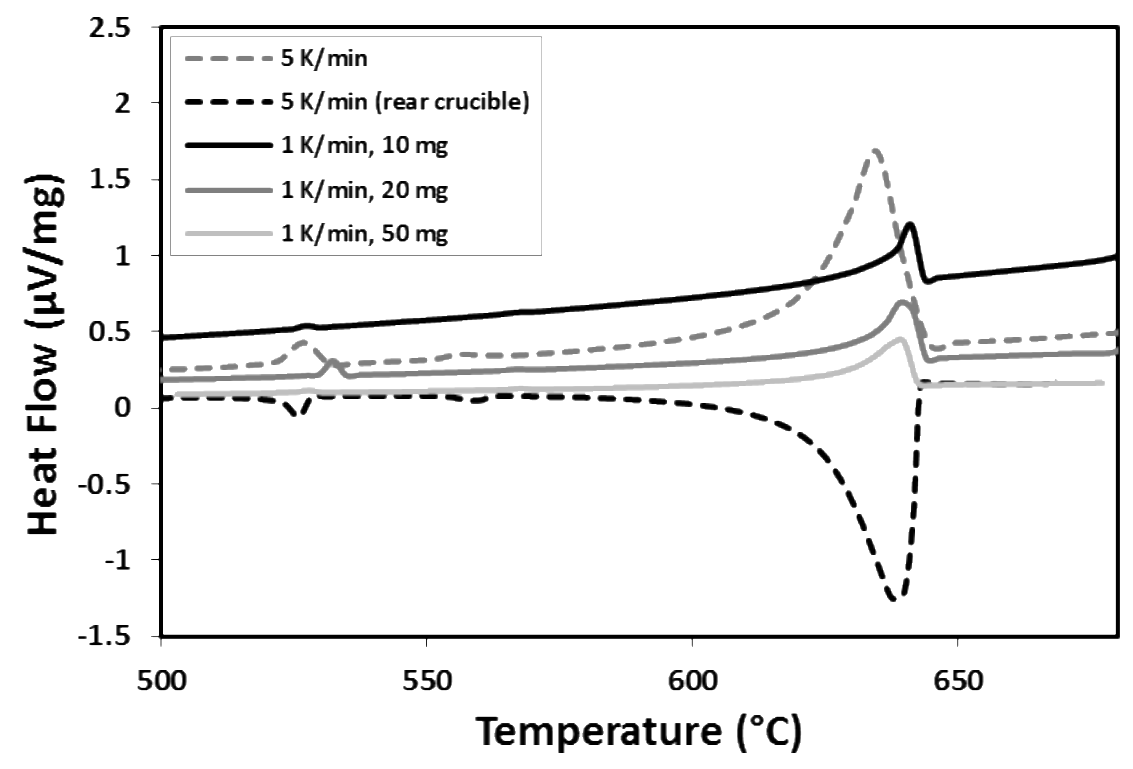

Figure 2 - DSC signals obtained during thermal analysis of B206 alloy using different crucible positions and different sample masses. 


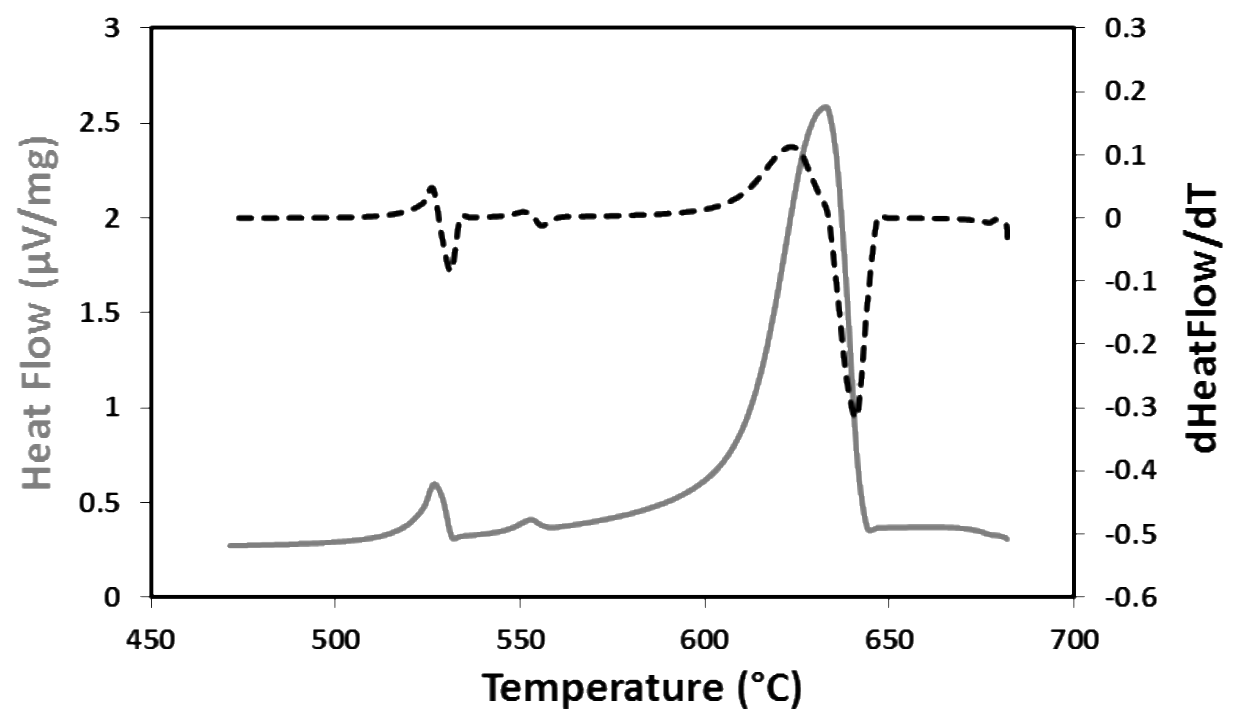

Figure 3 - Heat flow data together with its first derivative obtained during solidification of the examined alloy using a cooling rate of $8 \mathrm{~K} / \mathrm{min}$.

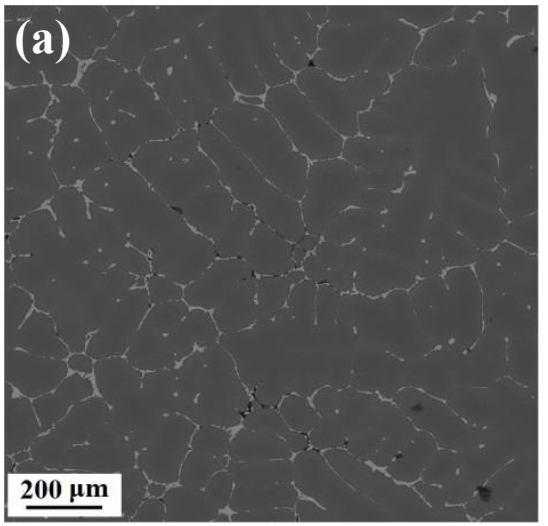

Al $K \alpha 1$

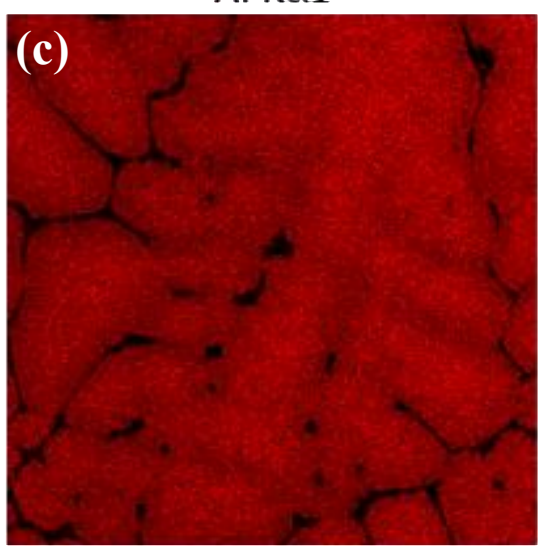

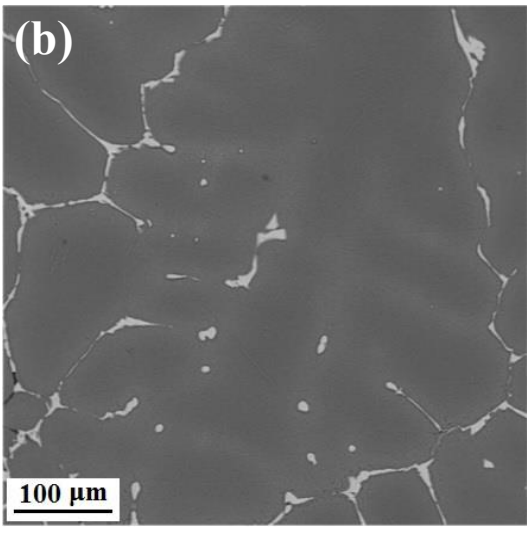

\section{$\mathrm{Cu} \mathrm{K} \alpha 1$}

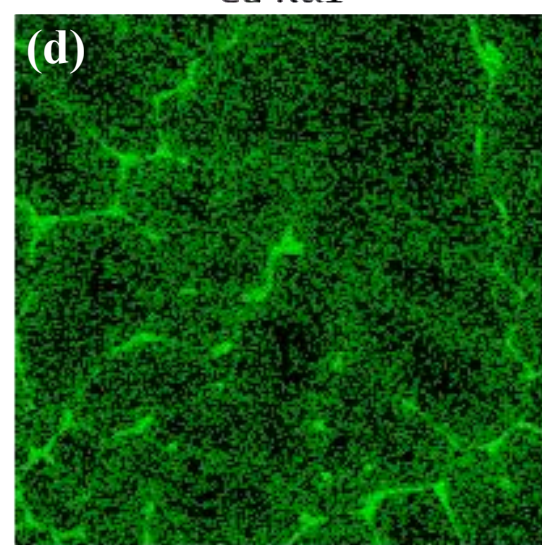

Figure 4 - SEM images ((a) and (b)) and elemental distribution maps ((c) Al-K series and (d) $\mathrm{Cu}-\mathrm{K}$ series) of the examined B206 alloy solidified with a cooling rate of $5 \mathrm{~K} / \mathrm{min}$. 

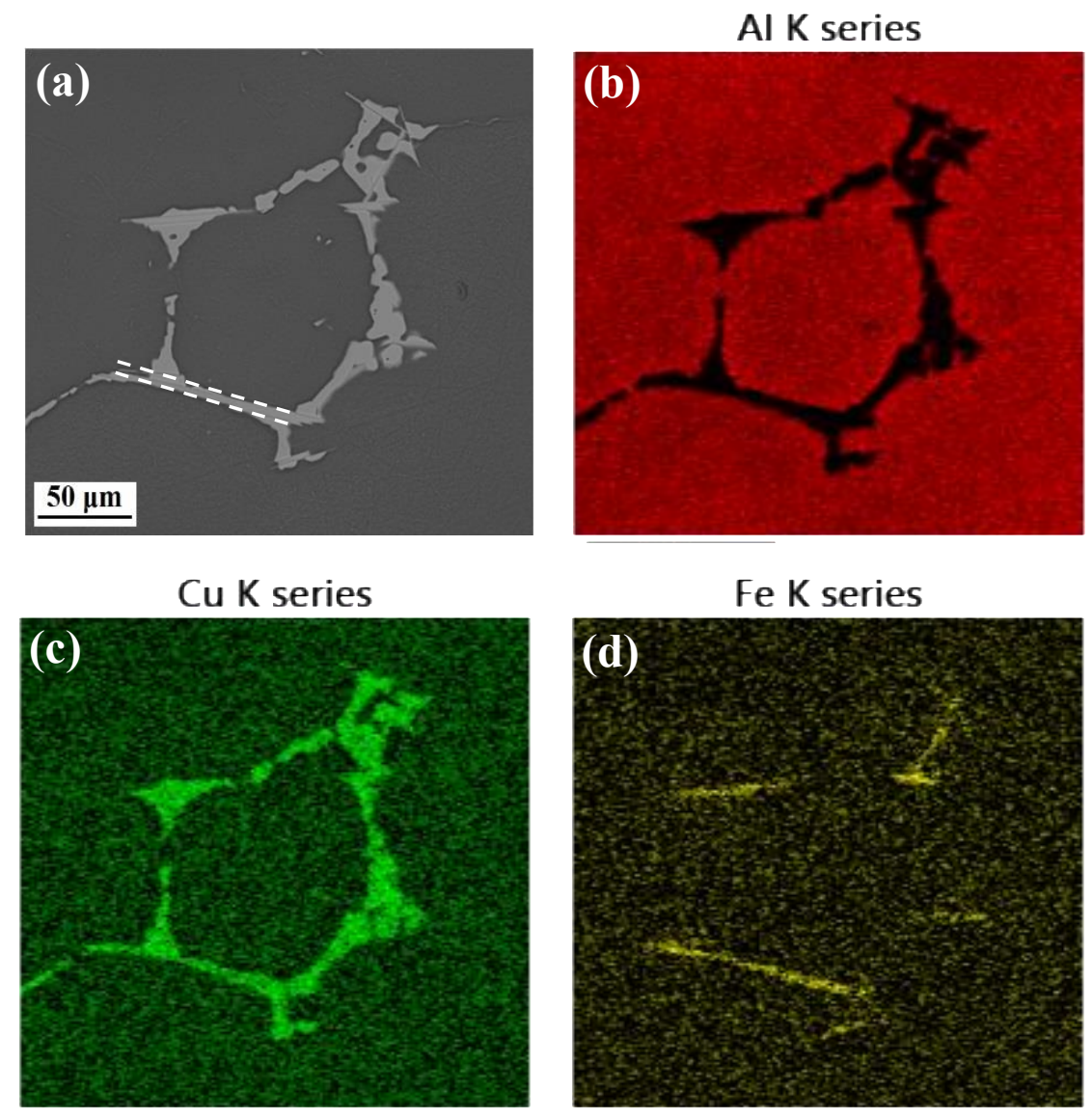

Figure 5 - SEM image (a) and elemental distribution maps ((b) Al-K series, (c) $\mathrm{Cu}-\mathrm{K}$ series, and (d) Fe-K series) of the examined B206 alloy solidified with a cooling rate of $8 \mathrm{~K} / \mathrm{min}$. Note the difference in resolution as compared to Figure 4. 


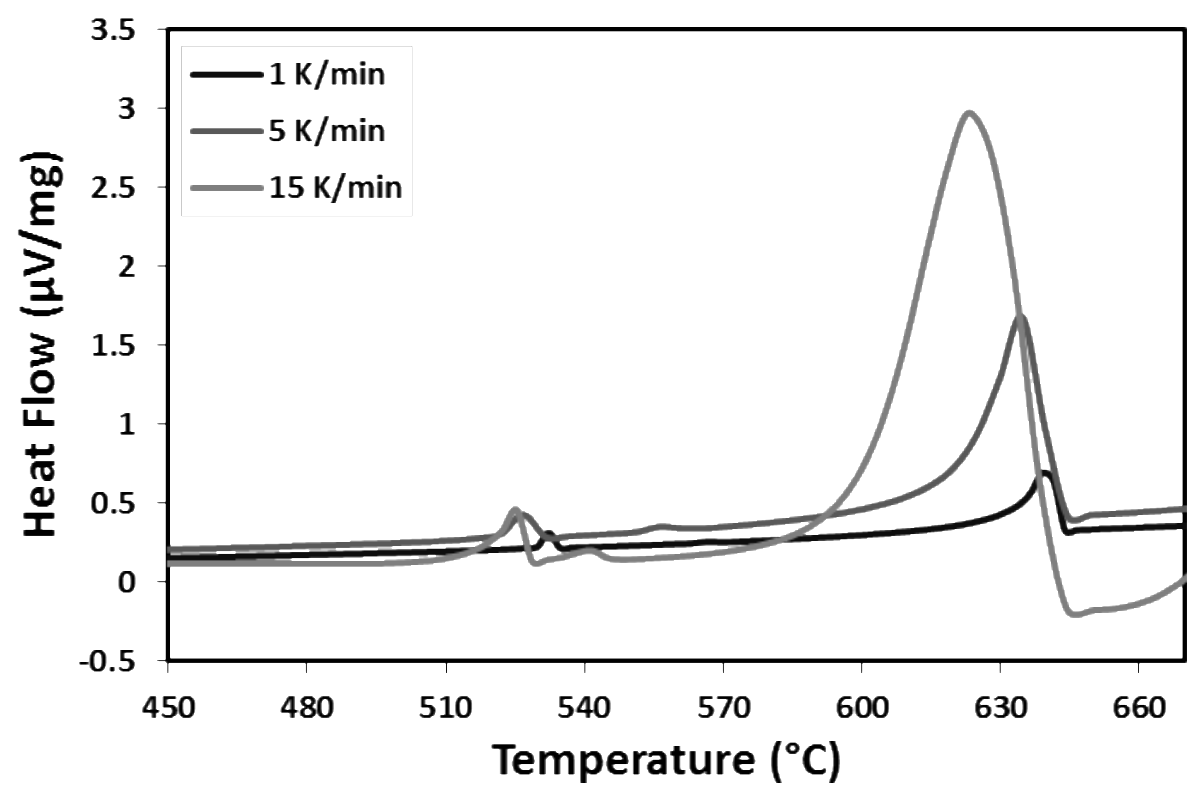

Figure 6 - DSC heat flow signals obtained during solidification of B206 under different cooling rates between 1 and $15 \mathrm{~K} / \mathrm{min}$.

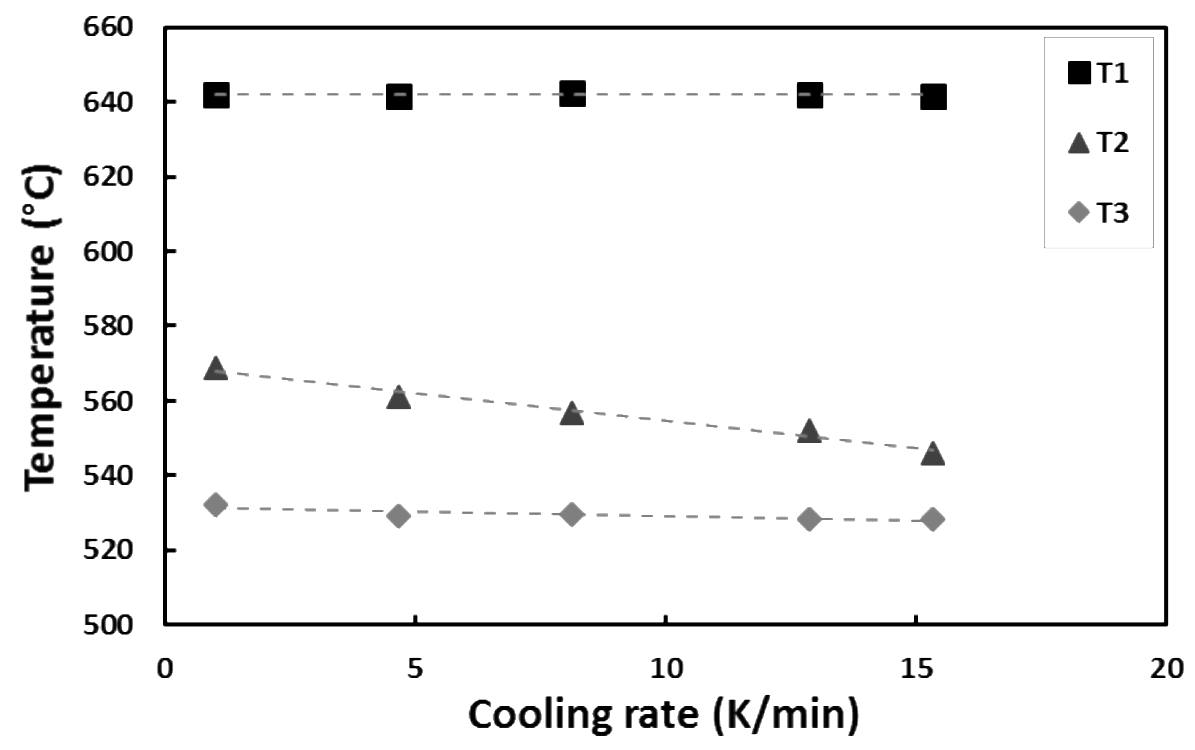

Figure 7 -The effect of cooling rate on the formation temperature of $\alpha$ phase $\mathrm{Al}$ (T1), intermetallic compounds (T2) and the eutectic reaction (T3). 


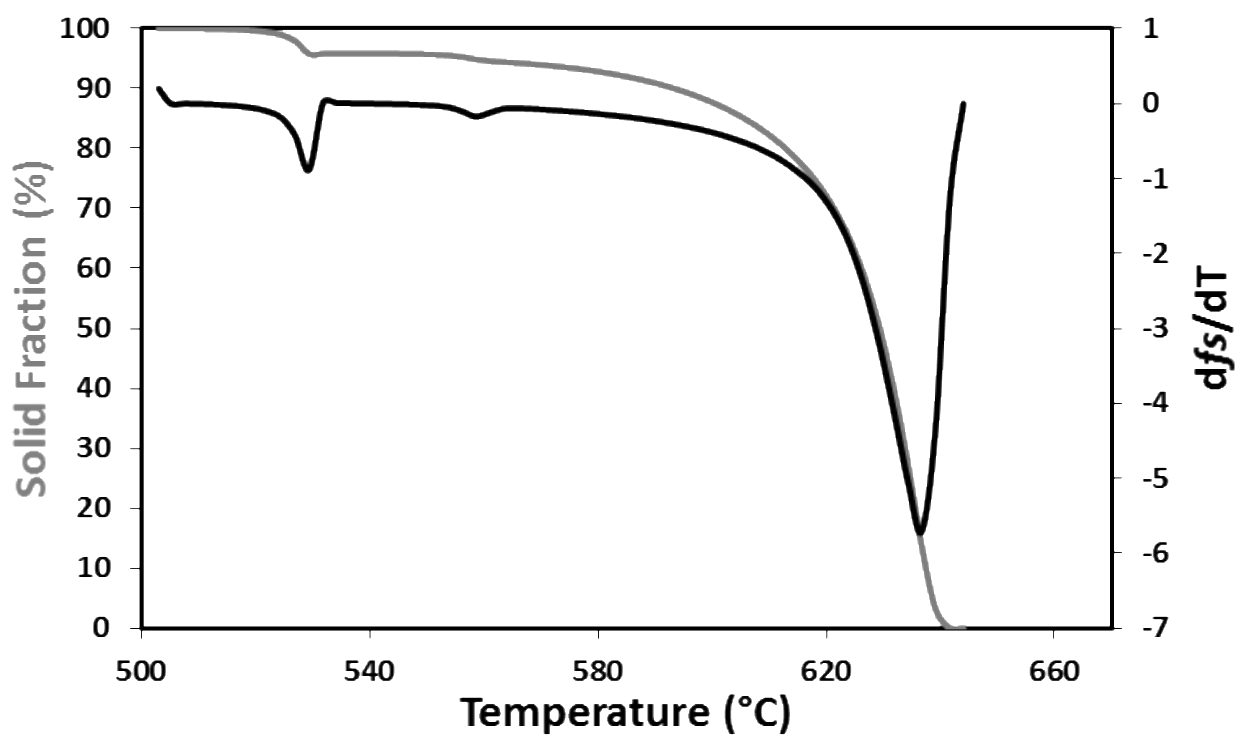

Figure 8 - The evolution of solid fraction together with its first derivative obtained through the DSC analysis of B206 solidification under the cooling rate of $8 \mathrm{~K} / \mathrm{min}$.

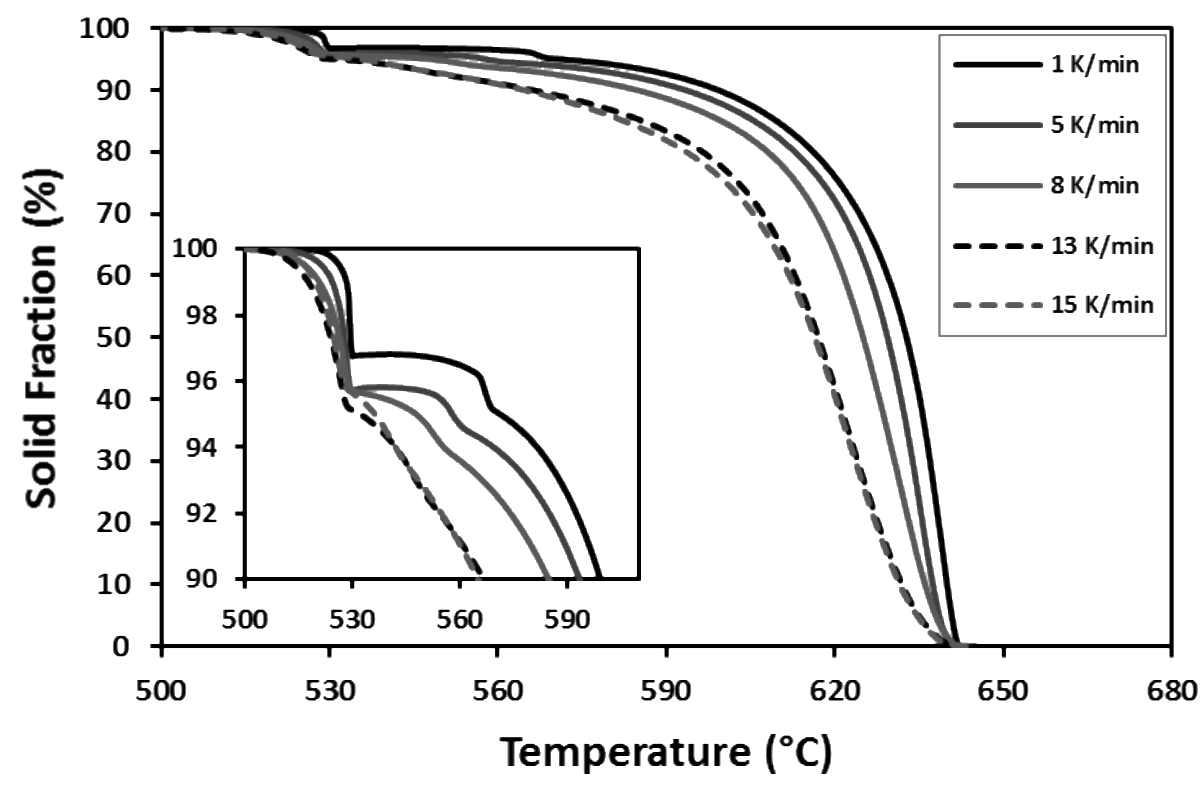

Figure 9 - The effect of cooling rate on the evolution of solid fraction during solidification of B206 alloy. 


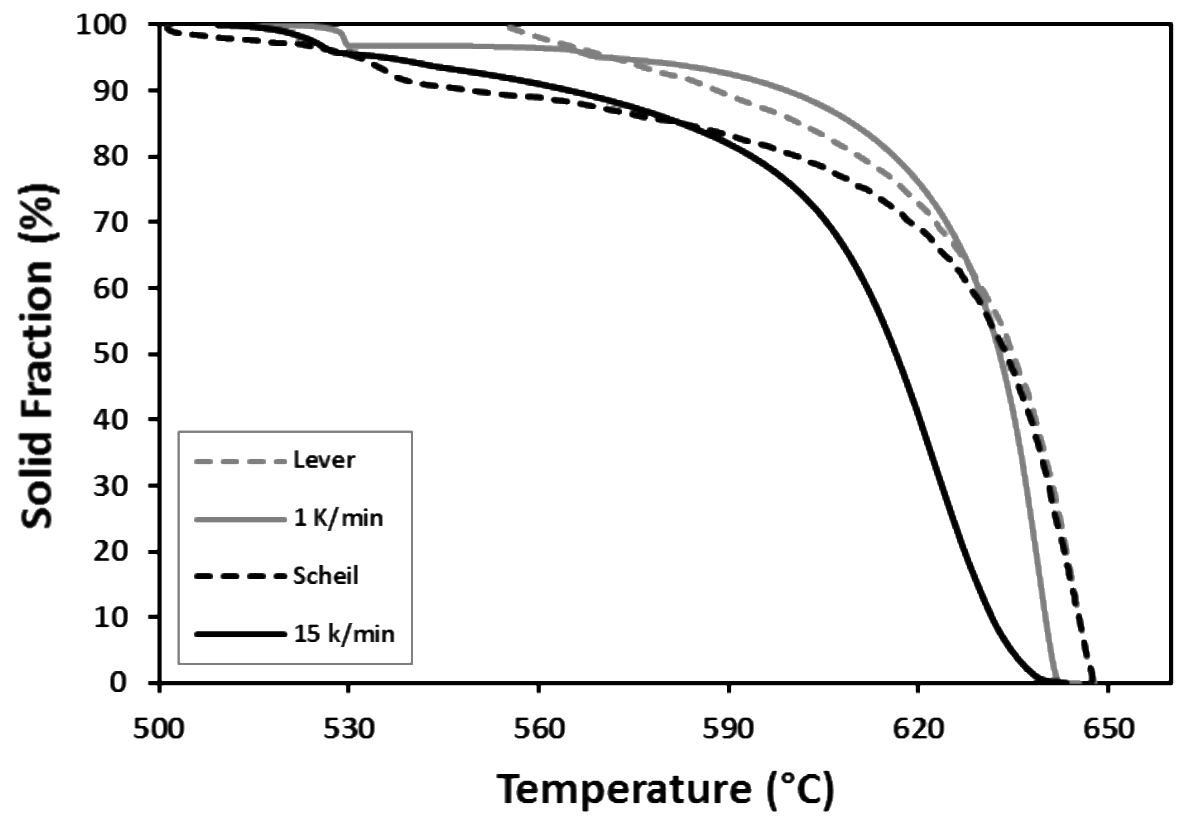

Figure 10 - Experimental and ThermoCalc modeling results for the evolution of solid fraction during solidification of B206 alloy. 

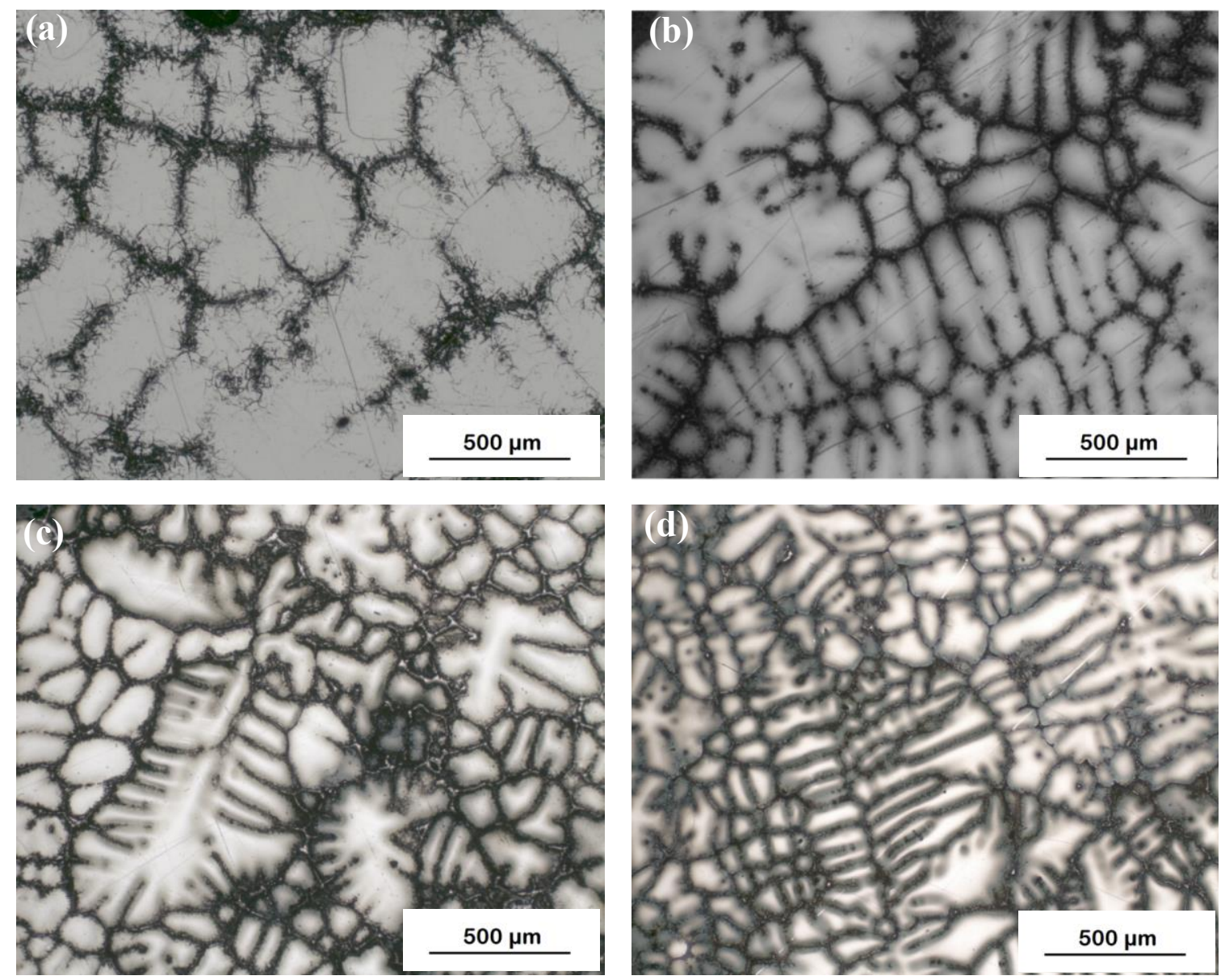

Figure 11 - Optical micrographs of DSC specimens solidified at cooling rates of (a) $1 \mathrm{~K} / \mathrm{min}$, (b) $5 \mathrm{~K} / \mathrm{min}$, (c) $8 \mathrm{~K} / \mathrm{min}$, and (d) $15 \mathrm{~K} / \mathrm{min}$. 


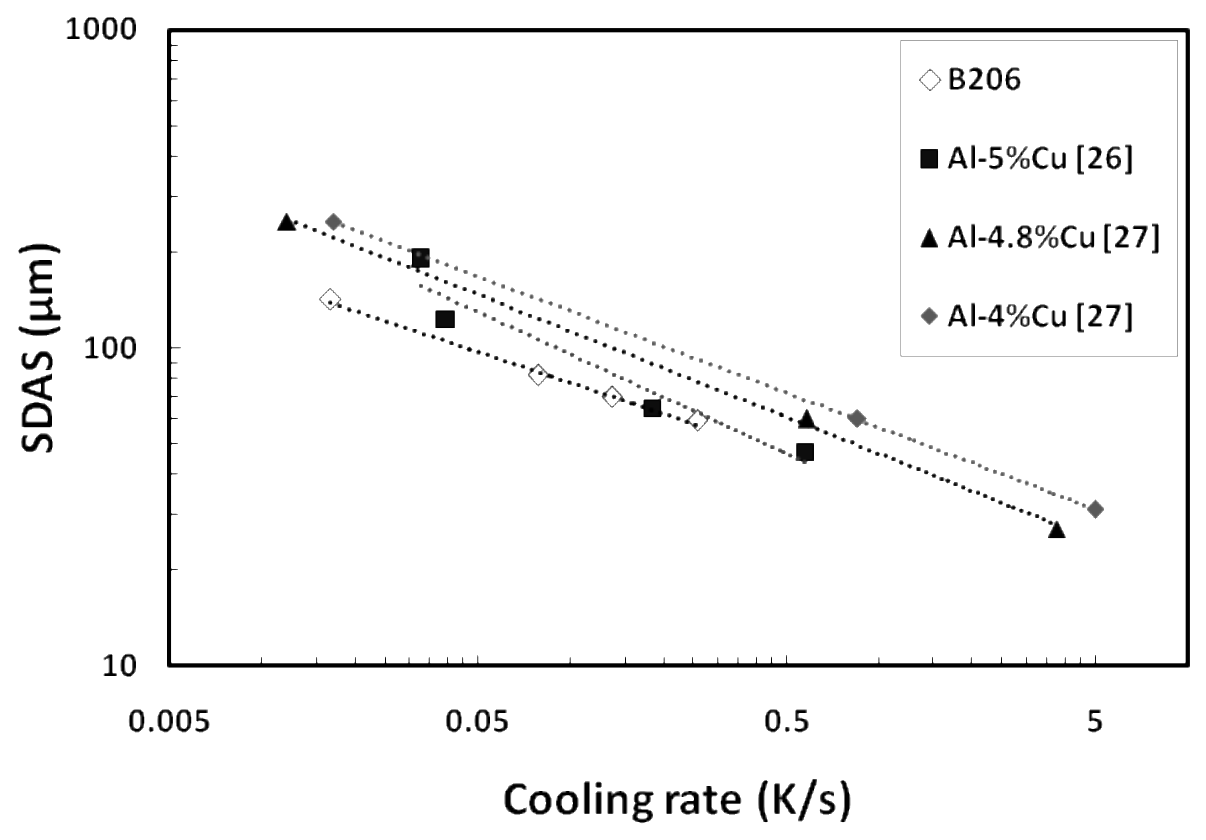

Figure 12- The evolution of secondary dendrite arm spacing with cooling rate in the examined B206 alloy and some other $\mathrm{Al}-\mathrm{Cu}$ cast alloys. 


\section{References}

[1] D. Carle, B. Gordon, Mater. Des. 20 (1999) 267.

[2] S. Das, W. Yin, JOM 59 (2007) 83.

[3] L. Backerud, C. Guocai, T. Jarmo, AFS 2 (1990) 266.

[4] J.F. Major, G.K. Sigworth, Trans. AFS 114 (2006) 117.

[5] F. D'Elia, C. Ravindran, D. Sediako, Can. Metal. Quart. 53 (2014) 151.

[6] M. Manivannan, D.O. Northwood, J.H. Sokolowski, 3rd International Conference on Integrity, Reliability and Failure, Porto/Portugal, 2009.

[7] F. D'Elia, C. Ravindran, Trans. Indian Inst. Metals 62 (2009) 315.

[8] H. Kamali, M. Emamy, A. Razaghian, Mater. Sci. Eng. A 590 (2014) 161.

[9] H.K. Kamga, D. Larouche, M. Bournane, A. Rahem, Metal. Mater. Trans. A 41 (2010) 2844.

[10] K. Liu, X. Cao, X.G. Chen, Metal. Mater. Trans. A 42 (2011) 2004.

[11] E.M. Elgallad, X.G. Chen, Mater. Sci. Eng. A 556 (2012) 783.

[12] D.G. Eskin, Q. Du, D. Ruvalcaba, L. Katgerman, Mater. Sci. Eng. A 405 (2005) 1.

[13] M.A. Talamantes-Silva, A. Rodríguez, J. Talamantes-Silva, S. Valtierra, R. Colás, Metal. Mater. Trans. B 39 (2008) 911.

[14] K. Liu, X. Cao, X.G. Chen, J. Mater. Sci. 47 (2012) 4290.

[15] H. Iwasaki, T. Mori, M. Mabuchi, K. Higashi, Acta Mater. 46 (1998) 6351.

[16] H.B. Dong, M.R.M. Shin, E.C. Kurum, H. Cama, J.D. Hunt, Fluid Phase Equilibr. 212 (2003) 199.

[17] H.B. Dong, R. Brooks, Mater. Sci. Eng. A 413 (2005) 480.

[18] N. D’Souza, M. Lekstrom, H.J. Dai, B.A. Shollock, H. B. Dong, Mater. Sci. Technol. 23 (2007) 1085.

[19] N. D’Souza, H.B. Dong, Scripta Mater. 56 (2007) 41. 
[20] N. D’Souza, H. B. Dong, Mater. Sci. Technol. 27 (2011) 325.

[21] U.R. Kattner, , K.W. Moon, J. H. Perepezko, DTA and heat-flux DSC measurements of alloy melting and freezing. US Department of Commerce, Technology Administration, National Institute of Standards and Technology, 2006.

[22] L. Backerud, Solidification characteristics of aluminum alloys. American foundrymen's Society, Des Plains, IL, 1986.

[23] M.A. Talamantes-Silva, A. Rodriguez, J. Talamantes-Silva, S. Valtierra, R. Colás, Mater. Charac. 59 (2008) 1434.

[24] K. Liu, X. Cao, X.G. Chen, Metal. Mater. Trans. B 43 (2012) 1231.

[25] Q.G. Wang, C. J. Davidson, J. Mater. Sci. 36 (2001) 739.

[26] D. Larouche, C. Laroche, M. Bouchard, Acta Mater. 51 (2003) 2161.

[27] S. Thompson, S.L. Cockcroft, M.A. Wells, Mater. Sci. Technol. 20 (2004) 194.

[28] H.K. Kamga, D. Larouche, M. Bournane, A. Rahem, Mater. Sci. Eng. A 527 (2010) 7413.

[29] J.A. Sarreal, G.J. Abbaschian, Metal. Trans. A 17 (1986) 2063.

[30] S. Nafisi, D. Emadi, R. Ghomashchi, Mater. Sci. Eng. A 507 (2009) 87.

[31] M.C. Flemings, Solidification Processing, McGraw-Hill, NY, USA, 1974.

[32] J.A. Horwath, L.F. Mondolfo, Acta Metal. 10 (1962) 1037.

[33] A.B. Michael, M.B. Bever. Trans. Metal. Soc. AIME (1954) 47.

[34] M. Solari, H. Biloni, J. Cryst. Growth 49 (1980) 451.

[35] J.B. Wiskel, K. Navel, H. Henein, E. Maire, Can. Metal. Quart. 41 (2002) 193.

[36] S.G. Shabestari, M. Malekan, Can. Metal. Quart. 44 (2005) 305.

[37] M. Easton, J.F. Grandfield, D.H. StJohn, B. Rinderer, Mater. Sci. Forum 519 (2006) 1675. 